\section{Commentary: Two birds with one stone: Combining procedures can be better than staging}

\author{
Karthik Thangappan, MD, and \\ David L. S. Morales, MD
}

The article by Nasirov and colleagues ${ }^{1}$ succinctly demonstrates the ability to combine 2 major procedures to reduce potential morbidity in a specialized patient population such as Marfan syndrome. The most common cardiac anomalies associated with Marfan syndrome involve aortic arch and/or valve pathology. Approximately 5\% of patients with pectus deformity are found to have Marfan syndrome, and one third of these patients will have cardiac anomalies. ${ }^{2}$ Typically, when patients without Marfan syndrome present with cardiac anomalies and pectus deformities together, concurrent surgical repair has gained popularity as it also addresses the compression of thoracic organs caused by the pectus deformity and resolves the consequent hemodynamic and respiratory compromise with generally positive outcomes. ${ }^{3}$ Furthermore, heart transplantation in pediatric patients with Marfan syndrome is exceedingly rare. According to the United Network for Organ Sharing database, from 1989 to 2019, 25 heart transplants were performed in patients with Marfan syndrome, with only $20 \%(n=5)$ being $\leq 18$ years of age at time of transplant. This article openly discusses the decision-making behind performing the first combined heart transplantation and Nuss procedure

From the Department of Cardiovascular Surgery, Cincinnati Children's Hospital Medical Center, Cincinnati, Ohio.

Disclosures: Dr Morales discloses the following: consultant and member of medical advisory board for Berlin Heart, Inc; proctor, consultant, and member of medical advisory board for Syncardia, Inc; national primary investigator for the 50/50 cc Syncardia Total Artificial Heart Food and Drug Administration trial; consultant for Medtronic, Inc (HeartWare Division); consultant for Abbott Medical, Inc (Thoratec Division); and consultant, investigator, and member of medical advisory board for CorMatrix Cardiovascular, Inc. Dr Thangappan has nothing to disclose with regard to commercial support.

Received for publication Nov 12, 2019; revisions received Nov 12, 2019; accepted for publication Nov 17, 2019; available ahead of print Jan 9, 2020.

Address for reprints: David L.S. Morales, MD, Department of Surgery, Department of Cardiovascular Surgery, Cincinnati Children's Hospital Medical Center, 3333 Burnet Ave, MLC 2004, Cincinnati, OH 45229 (E-mail: David.Morales@cchmc. org).

JTCVS Techniques 2020;1:100-1

2666-2507

Copyright (C) 2019 The Author(s). Published by Elsevier Inc. on behalf of The American Association for Thoracic Surgery. This is an open access article under the CC BY-NC-ND license (http://creativecommons.org/licenses/by-nc-nd/4.0/).

https://doi.org/10.1016/j.xjtc.2019.11.003

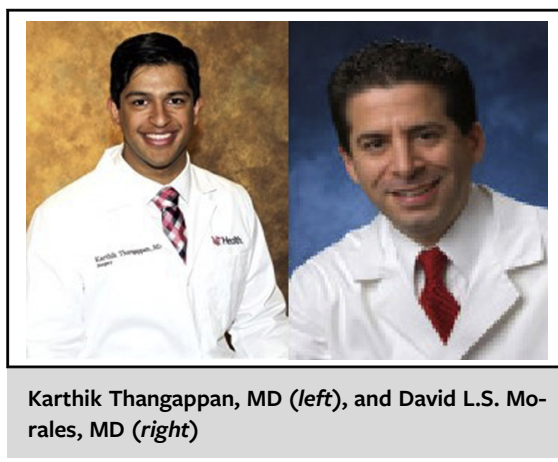

CENTRAL MESSAGE

Combining major cardiac procedures can often increase morbidity; however, in select patient populations, combining procedures can actually offer benefit that reduces overall morbidity and mortality.

in a pediatric Marfan syndrome patient with pectus excavatum.

Pectus repair usually can be delayed; however, when it causes cardiac complications due to mechanical compression, it should be repaired, especially if placing a new heart into the environment. We commend the authors for recognizing that by repairing the pectus deformity simultaneously with heart transplantation, it would increase intrathoracic space, thus allowing for maximization of donor-size eligibility and the ability to accept an offer sooner even if the donor organ was too large for the preoperatively compressed intrathoracic cavity.

The article by Nasirov and colleagues ${ }^{1}$ does a fine job succinctly describing the first case of orthotopic heart transplantation and simultaneous Nuss procedure in a pediatric patient with Marfan syndrome. The authors described their rationale for the decision-making in this case with clarity, including the decision to combine both procedures in one. This case is a great example of how the best solution to multiple complex problems can be a combined procedure, killing two birds with one stone.

\section{References}

1. Nasirov T, Dykes JC, Bruzoni M, Maeda K. Combined pediatric heart transplant and Nuss procedure in a patient with Marfan syndrome. J Thorac Cardiovasc Surg Tech. 2020;1:97-9. 
2. Behr CA, Denning NL, Kallis MP, Maloney C, Soffer SZ, Romano-Adesman A, et al. The incidence of Marfan syndrome and cardiac anomalies in patients presenting with pectus deformities. J Pediatr Surg. 2019;54:1926-8.
3. Media AS, Pilegaard HK, de Paoli FV. Combining correction of pectus excavatum and open heart surgery in a single-stage procedure. Ann Thorac Surg. 2020;109: e71-4. 